\title{
Does pragmatic beat syntax? \\ Evidence from focus accent placement in the semi-spontaneous speech of Italian learners of German*
}

\author{
Barbara Vogt (L’Aquila), Peter Paschke (Venice)
}

\begin{abstract}
In this paper, we investigate the prosodic marking of information structure by Italian L1 learners of German. We analyze two different contexts with non-final focus accents, i. e. narrow and broad focus contexts, mainly on sentence level while most studies discussing post-focal deaccentuation are restricted to noun phrases. For Italian learners, non-final placement of focus accents is likely to cause problems, given that in their L1, phonetic prominence is normally assigned to the last constituent in the verbal phrase. Our initial hypothesis was that the hypothetical "cognitive universal" requiring de-accentuation of given elements might probably guide the learners in realizing the correct pitch contour in contexts with a non-final narrow focus (and pragmatic de-accentuation of the final given constituent). By contrast, the de-accentuation of phrase-final lexical verbs in broad focus contexts was expected to cause more problems given that this typologically marked syntactic structure does not exist in Italian. However, in a previous study based on read speech, de-accentuation of final given elements was managed by intermediate Italian learners of German L2 only slightly better than realizing a non-final focus accent in all new contexts on the argument in OV structures (success rate of 55\% vs. 48\%, with no statistically significant difference). In other words, both types of non-final focus accents seem to be balanced at this intermediate stage of acquisition. In this contribution, our goal is to discover whether in semi-spontaneous speech one can find the same distributional patterns of non-final focus accents in this learner variety of Italian learners of German. To this end, we analyzed recordings of oral exams from the same 10 Italian university students that had taken part in the previous study. The analysis shows that in semi-spontaneous speech production too, there is evidence for the hypothesis that pragmatics does not "beat" syntax in prosodic acquisition. Besides, when the two different data types were compared, a very high intra-speaker correlation emerged between read and semi-spontaneous speech.
\end{abstract}

\footnotetext{
* This study was presented at the International Conference "La comunicazione parlata 2016 /Spoken Communication 2016" in Naples, 13-14-15 June 2016. The paper was submitted in November 2016 and definitively accepted in February 2018. We want to thank the reviewers for valuable comments on an earlier version of this paper. Both authors contributed equally to the manuscript. The final elaboration of sections 1-3 was supervised by Barbara Vogt, section 4 by Peter Paschke and the last section by both authors.
} 


\section{Introduction: focus accents in German and Italian}

The two languages under investigation in this contribution, Italian and German, identify the focus in a sentence through main sentence prominence (or nuclear stress). In the unmarked ${ }^{1}$ case, the word that bears nuclear stress corresponds to the last content word in the intonational phrase. Such pitch accent is referred to as the nuclear pitch accent. Phrase-final nuclear stress driven by phonology and prosodic representation is often described as "structural accentuation" (cf. Avesani et al 2015: 99; Maastricht et al 2016: 128). In broad focus contexts (all-new-contexts) the pitch accented word "projects" the focus over the whole constituent and is called by Uhmann (1991) the focus exponent (FE).

German: Was ist los?

[ich fahre nächste Woche nach berLIN.] ${ }^{2}$

Italian: Cosa succede?

[La settimana prossima vado a berLIno.]

'What's going on'?

'Next week, I'm going to Berlin.'3

But Italian and German are also subject to typological variation regarding a) the type of elements eligible to function as FE, that is the role of syntactic representation in assigning prominence $^{4}$ and $b$ ) the interaction with pragmatic factors relating to information structure.

a) In Germanic languages focus is realized typically on arguments (see specifically for German sentence accents Féry 2011, for a more general overview Truckenbrodt 2006, Gussenhoven 1992, Selkirk 2011). Hence, in a language like German, focus accents are often realized in nonfinal position, given that the non-finite verb forms of complex predicates (infinitives, participles) in main clauses as well as the whole predicate in dependent clauses normally show up in phrase-final position (compare below, example 2). This is sometimes described as syntactic "de-accentuation" (cf. Avesani et al. 2015: 99). The term de-accentuation (introduced into discussion by Ladd 1980) refers to positions in which - contrary to expectations - no intonational prominence is realized. To give an example, in "all new" contexts it is expected that the focus accent is assigned to the last content word (the prosodic head) in an intonational phrase. ${ }^{.}$If this

\footnotetext{
${ }^{1}$ In the following, we consider phrase final prominence to be the unmarked case (which is supported by data from language acquisition, cf. section 2). By contrast, "prosodically marked" signifies that the accent is not in rightmost position in an intonational phrase. Thus, we consider also non-final focus accents on arguments in verb-final sentences in German as prosodically marked. In other accounts, sentence internal nuclear stress can be "unmarked" as well, namely in broad focus contexts in which the placement of focus accents in non-final position is determined by syntax, e.g. in the case of nuclear stress on arguments, or on subjects with inaccusative verbs, that is in patterns that are not influenced by pragmatic factors, cf. Zubizarreta 2016.

${ }^{2}$ Here and in the following, the part of the sentence under focus is put in square brackets. The syllable to which phonetic focus is assigned is written in capitals.

${ }^{3}$ Unless otherwise indicated, the examples in this section are taken from Paschke/Vogt (2015).

${ }^{4}$ For definitions of information structural notions, see Krifka 2008, Baumann/Kügler 2015, Baumann/Riester 2013, Hartmann/Winkler 2013. In the following we use given or activated (Chafe 1976, 1994) in a very broad sense. The same holds for the dichotomy focus vs. background; in this regard we distinguish between broad focus (all-new- or out-of-the-blue-contexts), whereas narrow focus comprises other forms of not broad focus such as corrective, contrastive, and verum/falsum-focus.

${ }^{5}$ Note, however, that there are structures that show nuclear accent in non-final position in all-new-contexts, too. This is for instance the case in so-called thetic sentences, such as The telephone rang, Cruttenden (2006: 315).
} 
final focus accent fails to appear, a form of "de-accentuation" occurs. De-accentuation is related to phonology which allots prominence to a metrical strong position and makes expectations of prosodic prominence arise. Specifically syntactic de-accentuation means in our account that in "all new" sentences the rightmost content word in a phrase normally functions as FE and should be pitch accented, but in German, if the rightmost element is part of a complex predicate, the nuclear accent is shifted to a preceding argument. In comparable sentences in Italian the nuclear accent is likewise on the argument, but also in rightmost position:

(2)

$\begin{array}{ll}\text { German: } & \text { was ist passiert? } \\ & \text { [karl hat den ersten PREIS gewonnen.] } \\ \text { Italian: } & \begin{array}{l}\text { cos'è successo? } \\ \text { [carlo ha vinto il primo PREmio.] } \\ \text { English: }\end{array} \quad \text { 'What happened'? } \\ & \text { 'Carlo won the first prize' }\end{array}$

In Italian this kind of syntactic information has not to be taken into account. As highlighted by Bocci (2008) and Poletto/Bocci (2016), phenomena of integration of predicates in the accent domain of arguments and the complement vs. adjunct distinction are not observable. Focus accent can be assigned also to the predicate, if in rightmost position, by contrast to the Germanic languages which in this case shift the accent backwards on the argument (cf. Ladd 1996: 191):

(3) Italian:

non ho tempo. [ho un verbale da SCRIvere.]

'I haven't got time. I've got the minutes to write.'

non ho tempo. [ho da scrivere un verBAle.]

'I haven't got time. I've got to write the minutes.'

English: $\quad$ i don't have any spare cash. [i have a HOUSE to buy.]

i don't have any spare cash. [i have to buy a HOUSE.]'

In other words, while in Italian in broad focus contexts "structural" accentuation determined exclusively by prosodic constituency applies and assigns the nuclear pitch accent to the last content word in the intonational phrase, in German in all new sentences, focus accents are often realized in non-final position and syntactic information has to be taken into account.

b) Another context in which in German prosodically marked patterns (with non-final focus accents) arise is connected to information structure and pragmatics. Post-focal given information is de-accentuated (pitch accents are deleted or reduced) and nuclear stress is shifted to the left. (But see Kügler/Féry 2016 regarding German, Bocci/Avesani 2015, Grice et al 2005 regarding Italian for compressed post-focal pitch accents).

wer hat dir denn diese kette gegeben?

'Who gave you this chain?'

[KARL] hat sie mir gegeben.

By contrast, Italian speakers tend to avoid prosodically marked structures preferring other linguistic means related to word order alternations (Lombardi Vallauri 2010, Samek-Ludovici

\footnotetext{
6 The English examples are taken from Grice/Baumann (2007: 36).
} 
2010). ${ }^{7}$ In (5) normal linear word order has been changed in order to allow the constituent under narrow focus to be placed in phrase-final position designated for the most important information:

$$
\begin{aligned}
& \text { chi ti ha dato questa catenina? } \\
& \text { 'Who gave you this chain?' } \\
& \text { me l'ha regalata [ricCARdo.] } \\
& \text { to me it has given ricCARdo. } \\
& \text { 'It was given to me by ricCARdo'. }
\end{aligned}
$$

In this example, the narrow focus context is signaled by virtue of the marked, "focal" word order (Face/D'Imperio 2005). Simultaneously, the "togetherness" (Vallduví 1991: 295) of informational and prosodic focus in rightmost position is preserved.

To sum up, whereas in Italian nuclear stress is predominantly realized in phrase-final position, in German, in two contexts often non-final focus accents arise. For convenience, we call these two phenomena syntactic and pragmatic de-accentuation. Syntactic de-accentuation is connected to the argument structure of the verb meaning that in a main clause, parts of the predicate in phrase-final position, or in subordinate clauses the whole predicate, cannot function as focus exponent (FE) and in this case stress is shifted to the preceding argument. Pragmatic de-accentuation means that in Germanic languages like German and English given information gets deaccented in post-focal, phrase-final position while the nuclear pitch accent is shifted backwards.

For Italian learners of German, both types of de-accentuation are likely to cause problems and the following study aims to investigate if there are differences in prosodic acquisition regarding the two different contexts outlined above.

Most studies discussing post-focal de-accentuation look at the level within NPs (cf. e. g. Avesani et al. 2015, Rasier/Hiligsmann 2009, Maastricht et al 2016, for more details see section 2) whereas our study concentrates on the realization of non-final focus accents at the sentence level. It has been observed that in Italian, pragmatic de-accentuation within noun phrases (NPs) is strongly disfavoured (Ladd 1996: 177), while this claim is less strong in the case of whole NPs. For instance, the 11 Italian informants in Cruttenden (2006) showed no re-accentuation in the first 3 of 10 examples containing full NPs as given elements. ${ }^{8}$ Moreover, the above-mentioned studies were testing whether and to what extent specifically pragmatic de-accentuation can override "structural" accentuation, whereas we are investigating the acquisition of two different forms of de-accentuation, namely, the syntactic form compared to the pragmatic one.

\footnotetext{
${ }^{7}$ For instance, Ladd (1996: 179) gives the following examples with de-accentuation within NP: "Adesso faccio scorrere il TUO bagnetto" ("Now I'll run YOUR bath') vs. "Adesso faccio scorrere il TUO, di bagnetto") which receives a contrastive interpretation. Ladd states that the former is "considerably less acceptable" than the latter, a construction with right dislocation, though not impossible.

${ }^{8}$ For instance, no re-accentuation occurred in the following examples: Setting-response 1: [If you don't hurry up, you'll be late.] Me ne frego del ritardo. 'I don't care if we are late.' Setting-response 2: [A: Would you like to come to dinner tonight, I'm afraid it's only chicken.] B: Non mi piace il pollo. 'I don't like chicken'. (Cruttenden 2006: 318-320, 342). Another example with sentence internal narrow focus is the following taken from Grice et al (2005: 366): Mamma [è andata a balLAre] da Lalla, 'Mom went to dance at Lalla's', as an answer to a question like: What did Mom go to do at Lalla's? See Poletto/Bocci (2016) for other cases of non-final main prominence in Italian.
} 


\section{Focus accent in language acquisition}

As outlined in section 1, Italian is classified as a language with predominant unmarked "structural" accentuation, where "structural" means that in a prosodic domain (an intonational phrase) it is the last constituent which receives the highest prominence by default and that "prominence distribution is driven only by the phonological rules and by the prosodic representation" (Avesani et al. 2015: 99, cf. section 1). Languages which apply only "structural" accentuation are considered to be crosslinguistically the unmarked case. In Rasier and Hiligsmann $(2007,2009)$ markedness concerning accent systems is based on implications: Pragmatically determined sentence accent implies the presence of structurally determined sentence accent, but not vice versa. No language totally lacks structural constraints and relies on pragmatically determined constraints only, but there are languages that lack pragmatically determined accentuation and rely only on structural accentuation. The authors take Italian and Spanish as examples for languages with only structural rules and German, English and Dutch as languages with pragmatic/structural rules which range higher on the proposed markedness scale, cf. Rasier and Hiligsmann (2007: 53), see also Zerbian (2015), Avesani et al. (2015), Maastricht et al (2016).

The unmarkedness of phrase-final focus accents is also confirmed by data from language acquisition: in their L2 learner variety, speakers tend to accent the last content word of an utterance irrespective of their L1, and regardless of its pragmatic status as given/new or its syntactic category (predicate or argument, cf. Grosser 1997, Ramirez Verdugo 2002, Gut 2009, Gut/Pillai 2014, among others). For instance, even German learners who use pragmatic de-accentuation in their L1, fail to do so in acquiring English and overgeneralize end-focus even at advanced stages of language acquisition (O'Brien and Gut 2011, German learners of English). Compare e. g. the following example given in Grosser (1997) who observed Austrian pupils (age: 1012) in their first two years of English as a foreign language. To the teacher's question "Is anybody ABsent today?" some pupils answered "NObody is ABsent" instead of realizing narrow focus with de-accentuation of the final word "absent" like in German "NIEmand ist abwesend".

Thus, prosodic acquisition of L2 focus accentuation seems to start with an unmarked phrasefinal accentuation.' In languages like German this unmarked accentuation interacts with other rules/constraints causing marked structures. In literature on prosodic acquisition it has often been highlighted that - according to Eckman's Markedness Differential Hypothesis (MDH, Eckman 1987) - marked structures are difficult to transfer into the L2, whereas unmarked L1 structures might lead to negative or positive transfer (cf. also Rasier/Hiligsmann 2007, 2009). This hypothesis has been tested in several studies and seems to be confirmed by the asymmetry in the learner varieties of speakers with typologically different first languages: speakers whose L1 mainly follows unmarked phrase-final accentuation - so-called non-plastic languages (Vallduvì 1991), such as Italian - have more difficulty perceiving and producing correct focus accents in an L2 with pragmatic de-accentuation than vice versa. This has been documented by data from Italian L1 learners of German L2. In the experiment conducted by Avesani et al. (2015), the Italian L1 learners of German rarely de-accent final given elements (and thus rarely

\footnotetext{
${ }^{9}$ Féry (2013) assumes a general alignment constraint for focus, which interacts on a language-specific basis with other constraints.
} 
produce the correct accentuation), while German L1 learners of Italian correctly assign phrasal accent to the rightmost content word. This asymmetry is explained by the authors in terms of markedness: whereas the German L1 speakers must learn unmarked structures in Italian L2, Italian L1 speakers must learn marked ones in German L2 (Avesani et al. 2015: 111)..$^{.0}$ In acquisitional terms, there is negative transfer from Italian L1 to German L2, and this is what causes the asymmetry in the learning process. Similar results were obtained with native French L1 learners of Dutch L2 (Rasier/Hiligsmann 2009).

\section{Previous research}

In previous research, we hypothesized that Italian L1 learners should have less difficulty acquiring pragmatically determined rather than syntactically determined de-accentuation. From a typological point of view both types of de-accentuation are considered to be more marked than structural, i. e. phrase-final accentuation. However, "givenness" is often also interpreted as some sort of cognitive, pre-linguistic universal, displaying an iconic value. People should be able to identify givenness in their discourse even when speaking in a foreign language and should also be able to switch the related acoustic parameter on or off correctly: that is, they should be able intuitively to relate focus to acoustic prominence and givenness to absence of acoustic prominence. ${ }^{11}$ Indeed, pragmatic de-accentuation is observed in many languages, and as already mentioned, under certain circumstances it would seem to be possible in Italian too, at the sentence level (Cruttenden 2006, Ladd 1996). By contrast, in the case of syntactic deaccentuation, learners have to identify (according to a language-specific rule without any iconic value) the non-final correct focus exponent that projects the focus feature across the whole focus domain and they have to de-accentuate the final element in a typologically marked syntactic structure (cf. Nübling 2006): isolating the infinite parts of a complex verb (separable prefixes, particles, infinitives etc.), in order to put them phrase-finally into the second "bracket" is difficult for intermediate learners even besides the prosody.

In order to prove the validity of the hypothesis that there is a learning advantage related to the relationship between givenness and lack of prominence and its alleged status as cognitive universal (Cruttenden 2006) which thereby renders pragmatic de-accentuation easier to acquire than syntactic de-accentuation, an experiment was conducted (in February 2014) with 10 Italian L1 learners of German (level: B1/B2), aged 21-4, 1 male, 9 female subjects. The subjects were given a reading task consisting of 35 sentences with non-final focus accents and 5 sentences with final focus accents. The sentences containing narrow or broad focus in the answers were elicited by suitable questions (for details, see Paschke/Vogt 2015). The results showed that

\footnotetext{
10 For the strong tendency of Italian speakers not to de-accentuate given elements in their L1, see Swerts, Krahmer/Avesani 2002, Avesani/Vayra 2005.

${ }^{11}$ See Cruttenden (2006) for the relation between de-accentuation and given information through time. E. g. already Walker (1781: 15) wrote: "Those things with which we suppose our hearers to be pre-acquainted we express by such a subordination of stress as is suitable to the small importance of things already understood", cit. Cruttenden (2006: 314). Cf. also Chen (2005) based on Gussenhoven (2004) for hypothesis regarding universal tendencies in the use of intonation. According to these approaches a so called "effort code", the informational interpretation of which is emphasis or focus, is "universally" related to information structure: Pitch is used by the speakers in order to highlight important elements of the message and vice versa to downgrade the significance of less important elements.
} 
Italian L1 learners of German do indeed have difficulty producing non-final focus accents correctly (ca. $50 \%$ success rate), whereas the success rate for both types of de-accentuation was fairly similar (cf. fig. 1).

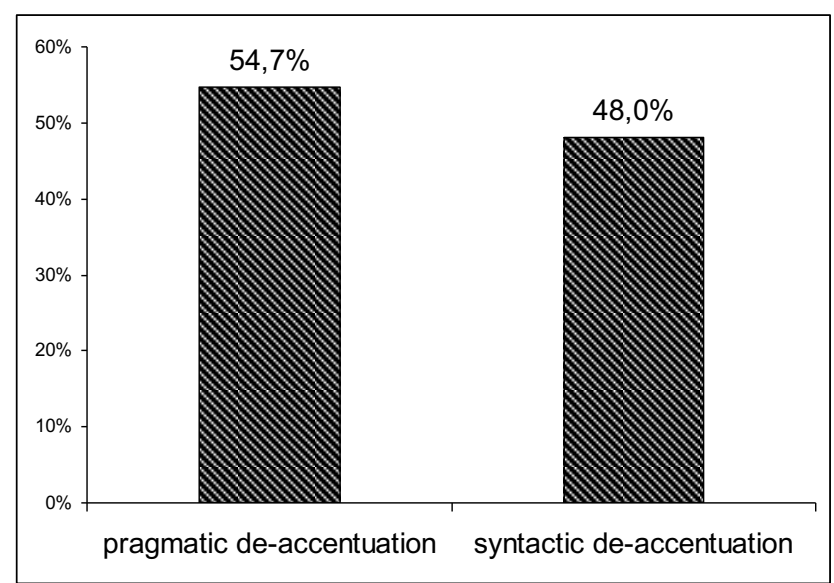

Fig. 1 Success rate of pragmatic and syntactic de-accentuation (Paschke/Vogt 2015)

\section{Current research}

\subsection{Hypotheses}

Subsequent to these results, we decided to do a follow-up study designed to verify the idea that also in semi-spontaneous speech both types of de-accentuation show up together and that there is no cognitive advantage in favour of pragmatic de-accentuation. To this end, we examined recordings (collected in January 2014) of oral examinations of the same test persons that had taken part in the elicited speech study in order to make possible an intra-speaker comparison between the two types of dataset. For methodological reasons (cf section 4.4.) we concentrated on the non-final focus accents actually realized by the test persons. The following hypotheses are to be tested:

A. The test subjects do not use non-final focus accents at random, but for pragmatic or syntactic de-accentuation. Thus we expect significantly more correct than incorrect occurrences of nonfinal focus accents.

B. For the test subjects the pragmatic de-accentuation is not easier to acquire than the syntactic one. So we predict:

B.1 a similar number of correct syntactically and pragmatically determined de-accentuations in the test population as a whole;

B. 2 a significant correlation between correct syntactically and pragmatically determined deaccentuations within the single test subjects.

C. The ability to realize non-final accents is independent of the experimental setting and the speech style. Therefore we expect a significant intra-speaker correlation between elicited (read) speech and semi-spontaneous speech in terms of the amount of correct non-final focus accents.

\subsection{Subjects}


The subjects (cf. Paschke/Vogt 2015: 99) were 10 learners of German (aged 21-24, 1 male and 9 female) with Italian as L1. All students were enrolled in a BA degree course in foreign languages (German plus another language) at the University of Venice and were successfully taking their second year's German language exam. All of them declared that Italian was their only mother tongue, that they had been learning German from 5 to 8 years at school and that their actual level within the Common European Framework of Reference for Languages was B2 (which is also the level required at the end of the second year). Only one student (TS08) had studied in Germany for a long period (6 months on an Erasmus scholarship), while two other students reported stays in Germany of 2 (TS04) and 3 months (TS01) respectively. None of the other subjects had ever spent more than a month in a German-speaking country.

\subsection{Procedure}

The recordings used for the present study form part of an informal corpus of oral examinations collected by the second author of this paper. At the time of recording (January 2014) they were not intended to be used in the present study; however they have been selected for the present study as they offer the chance to examine semi-spontaneous oral productions of the same test persons who had taken part (February 2014) in the read speech experiment described in section 3 . The oral examination was the final part of second year's German language exam and could be taken only by the students who had passed the written components (oral comprehension, written production, grammar test, questions about German syntax, translation). The speech style can be described as semi-spontaneous because the topics of the conversation were not free, but corresponded to those discussed in the language classes during the academic year (e. g. work and internships, studying abroad, online shopping, genetic engineering, climate change, old and new forms of partnership etc.). As prompts, the discussion was based on three pictures about one topic and on a short text passage (6-8 lines) on another topic, which were handed out to each student about 20 minutes before the assessment. During preparation the student had no access to dictionaries or other sources of information, but was allowed to take notes that could be used during the examination itself. The students were invited to talk for 4-5 minutes about the pictures and their subject (in a more monological form), afterwards they must read aloud the text, summarize it in their own words and then engage in an interaction with the two examiners (one of them was the second author of this paper). The duration of each oral examination was about 15 minutes, whereas the total duration of all ten recordings - excluding the preliminaries - amounted to $2 \mathrm{hrs}$. and 2 min., which were evaluated for the present study.

\subsection{Evaluation}

First of all we decided to search in the recordings only for utterances in which the test subjects had actually realized non-final focus accents. This restriction is justified by the fact that in semispontaneous speech, utterances of L2-learners are often split in many intonation phrases, sometimes with a separate IP for every single content word. Especially sentence-final predicates are subject to this phenomenon, probably because they require a special attention by (Italian) learners of German. An example is the following utterance of test subject 1 (TS01, 00:50):

(6) ICH würde- $(0.3 \mathrm{sec}$.$) das ER- un:: das ZWEIte äh bild- äh: ausWÄHlen,$
Ste, 
I would the first and the second picture choose

'I would choose the first and the second picture'

The whole utterance is split in 4 intonation phrases by means of filled (“äh”) and unfilled pauses as well as by final pitch movements. ${ }^{12}$ Each phrase has got its own nuclear accent (indicated by capital letters). Based on the context we can assume that there is a narrow (contrastive) focus on "erste" (first) and "zweite" (second). If the whole utterance had been expressed fluently, there should have been pitch accents (focus accents) on these two words, but not on "ich" (I) and "auswählen" (choose). On the other hand, even L1-speakers sometimes have to search for the right final predicate and, due to such a hesitation, build an independent IP on the final predicate. So it is not clear if similar utterances should be classified as correct or incorrect. In addition, in spontaneous speech of L2 learners disfluency is so frequent that similar problematic utterances could not simply be discarded. Therefore we restricted the analysis to utterances with actually realized non-final focus accents.

All occurrences of non-final focus accents were retrieved by means of both auditory analysis and additional acoustic control in Praat. The retrieved utterances were transcribed with Folker 1.2, following GAT 2 (Selting et al. 2009). Both raters (the authors of this paper) searched and transcribed those utterances independently. A total of 250 utterances were found by at least one of the raters, but $25(10 \%)$ of them were discarded because the two raters did not agree about the (final or non-final) position of the nuclear pitch accent. ${ }^{13}$

Subsequently, these accents were classified by the raters, again in a multi-step procedure starting from independent ratings and aiming at consensus. If the realized non-final accent was judged to be correct in relation to the context-based expected position of the nuclear pitch accent, we further classified it as either pragmatically or syntactically determined focus accent. Otherwise it was classified as incorrect realization. A wrong lexical stress (on the expected word) was not considered as incorrect.

Correct realization of a pragmatically determined non-final focus accent means that, based on the context, there is a (non-final) narrow focus and that the realized nuclear accent (signalled by capital letters) is correctly placed on the focussed word (indicated by square brackets): ${ }^{14}$

\section{Exam2: haben sie selbst schon ein praktikum gemacht}

TS03: ich habe [ZWEI] praktika gemacht-äh,

I did [TWO $]_{\mathrm{F}}$ internships (TS03, 08:02)

\footnotetext{
12 The final pitch movement of the intonation phrase is indicated according to GAT2:

$?=$ high rising

,$=$ rising

$-=$ invariable

$;=$ falling

.$=$ deep falling

13 The problems that can arise in perceiving the placement of nuclear accents are explained in Paschke/Vogt (2015: 100f.).

14 In the following examples we only sign primary accents. The context is given in italics and without prosodic annotation.
} 
In this first example, the examiner asked: Did you yourself do an internship? The examinee's answer contains a correct narrow focus accent on the number "two"15.

In the next example, the examinee is talking about young people with internships instead of regular employment who don't have enough money to buy their own homes. It is an example of the correct realization of a syntactically determined non-final focus accent:

TS03: [um ihre EIgenes- ähm HAUS zu kaufen; $]_{\mathrm{F}}{ }^{16}$

[in order to buy their own HOUSE] $]_{\mathrm{F}}$ (TS03, 07:09)

In (8) there is a broad focus on 'in order to buy their own house', but in German the focus accent is expected on the argument Haus and not on the rightmost content word kaufen.

Incorrect realizations of non-final nuclear pitch accents can be of different kinds which are not distinguished in this analysis. First of all, the expected focus accent can be final (thus a nonfinal nuclear accent is necessarily incorrect) like in (9) or it can be in a different non-final position like in (10). Moreover, the realized nuclear accent can be outside a narrow focus (derived from the context) like in (9) or inside a broad focus, but not on the expected focus exponent, like in (10).

TS08: *ich hab mit DEUTsche [gelebt-äh-]

*I [lived] $]_{\mathrm{F}}$ with GERmans (TS08, 09:27)

In the preceding utterance "Germans" was contextually given. The new information was that the student had actually lived with them. The context-based narrow focus is on "gelebt" (lived), i. e. final, whereas the realized nuclear pitch accent is non-final and outside the narrow focus.

TS03: *äh [noch bei IHren eltern wohnen, $]_{\text {}}$ *[still live with THEIR parents $]_{\mathrm{F}}$ TS03, 07:00

In (10) test subject TS03 is again talking about young people with little money who still live with their parents. The context suggests a broad focus and the expected focus exponent is the nominal head ("Eltern", parents) of the (non-final) argument. The realized nuclear accent is non-final, but not on the right word. It falls inside the broad focus, but not on the expected focus exponent. In this perspective, the accent placement is analyzed as error in the determination of

\footnotetext{
15 Here are some typical contexts of pragmatically determined non-final focus accents realized by the test persons: a) de-accentuation of elements given in the task, e. g. de-accentuation of the topic ("Arbeit") which is displayed on the task sheet: ,äh das PASST-äh- 'h am BESten zum thema Arbeit also;” (TS02, 03:10); b) answer to a whquestion on the task sheet (which photo matches best?): „meiner meinung nach passt foto (-) EINS am besten,” (TS03, 02:46); c) rephrasing with expansion and focus on new word: „mehr produZIEren, mehr ESsen produzIeren-" (TS06, 02:25); d) focus on alternatives: ,und sie werden äh nIcht oder äh KAUM bezahlt,” (TS03, 05:40); e) de-accentuation of elements mentioned or activated earlier, e. g. bücher ('books') previously activated by buchladen ('bookstore', 08:04): ,und sie möchte lieber perSÖNlich bÜcher kaufen.” (TS01, 08:31); f) verum focus: „es GIBT das probleme;” (TS07, 13:49), g) falsum focus/negation of given elements (Lösung, 'solution' was expressed immediately before): "für vIele LEUte, ist es NICHT eine 1Osung," (TS06, 02:52). De-accentuation

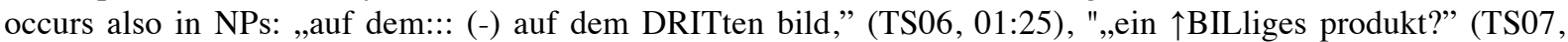
13:52). According to GAT2, postfocal/postnuclear secondary accents are marked by capitalizing the syllable nucleus (see examples a, c, e, g).

16 Please notice that the test subject (probably due to problems with speech planning) splits this short utterance into two intonation phrases separated by the filler ähm.
} 
the focus exponent. Alternatively, based on the realized accent, it could be classified as incorrect narrow focus. Incidentally, nuclear accents on prenominal adjectives, demonstratives and numerals instead of nominal heads are frequent among advanced Italian learners of German and - to our knowledge - still await an explanation.

\subsection{Results}

Among the 225 utterances in which both raters agreed about the non-final position of the focus accent, 11 could not be classified as pragmatically or syntactically correct or as incorrect because of interrupted utterances, insufficient context or rater disagreement. The remaining 214 utterances were classified as illustrated in table 1.

\begin{tabular}{|l|c|c|}
\hline & $\begin{array}{c}\text { Correct } \\
\text { realizations }\end{array}$ & $\begin{array}{c}\text { Incorrect } \\
\text { realizations }\end{array}$ \\
\hline Pragmatically determined non-final focus accents & 94 & - \\
\hline Syntactically determined non-final focus accents & 89 & - \\
\hline Total & $183(86 \%)$ & $31(14 \%)$ \\
\hline
\end{tabular}

Table 1: Classification of 214 utterances with non-final focus accents

Taking the test population as a whole, two observations can be made:

1. There are far fewer incorrect accents (14\%) than correct ones $(86 \%)$, which means that we can confirm our hypothesis (A) that the test population does not use non-final accents at random $\left(\chi^{2}=107.96, \mathrm{p}<.001\right)$.

2 . The correct accents are very evenly distributed between pragmatic (94) and syntactic ones (89). Therefore we can confirm hypothesis B.1 that for the test subjects the pragmatic de-accentuation is not easier to acquire than the syntactic one.

Let us now look at the single test subjects ordered by the number of correct non-final focus accents in figure 2 . When the number of correct pragmatic and syntactic accents is compared, it can be noticed that they occur simultaneously, with sometimes one and sometimes the other type prevailing, especially in the middle part of the chart. Spearman's rank correlation score is 0.43 (a medium value), so there seems to be a correlation between the two types of accents, although it is not statistically significant $(\mathrm{p}=0.21)$. 


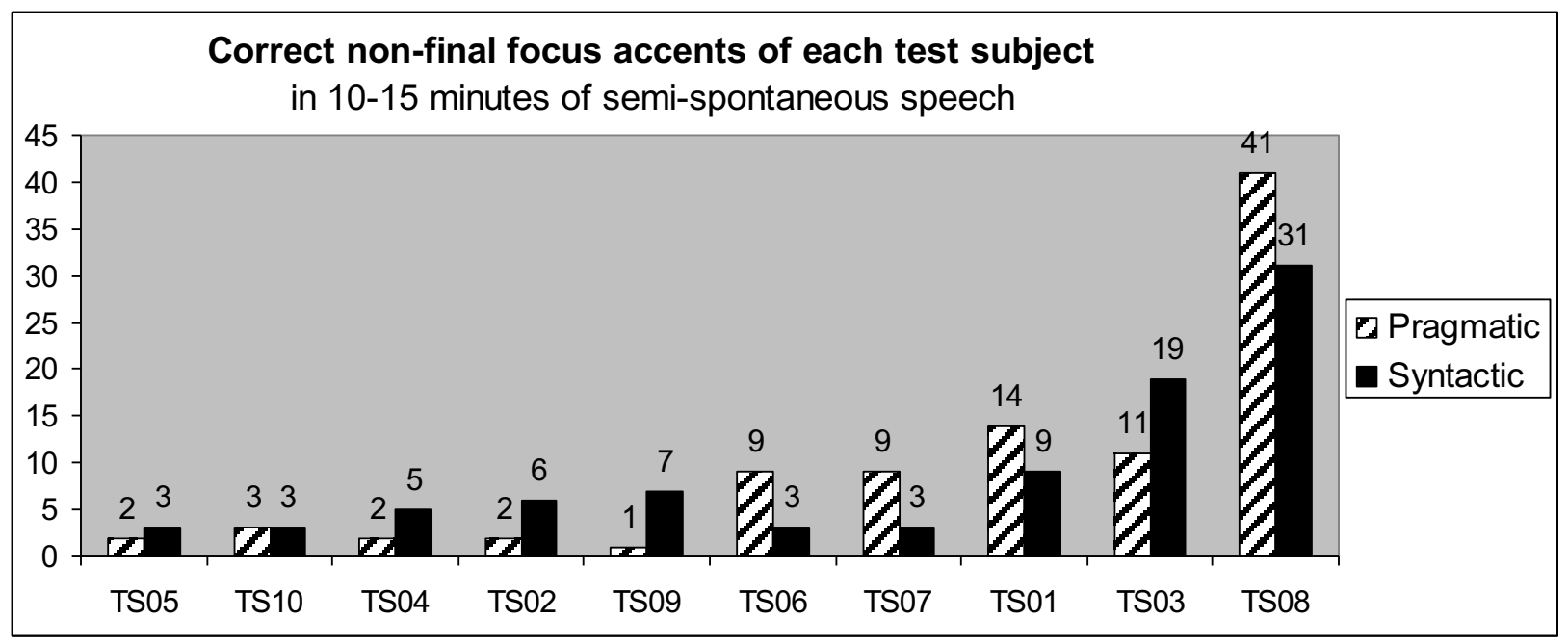

Figure 2: Number and type of correct non-final focus accents for each test subject (TS = test subject)

The same correlation can be observed in the dispersion chart of fig. 3, with the regression line indicating the possible relationship between the two types of correct realizations. Its inclination would suggest a proportion of about 4 correct pragmatic accents every 3 correct syntactic accents, but the small number of dots ${ }^{17}$ and their distance from the line make reliable generalizations impossible. Therefore we must reject hypothesis B.2 that predicted a significant correlation between the two types of de-accentuation within the single test subjects.

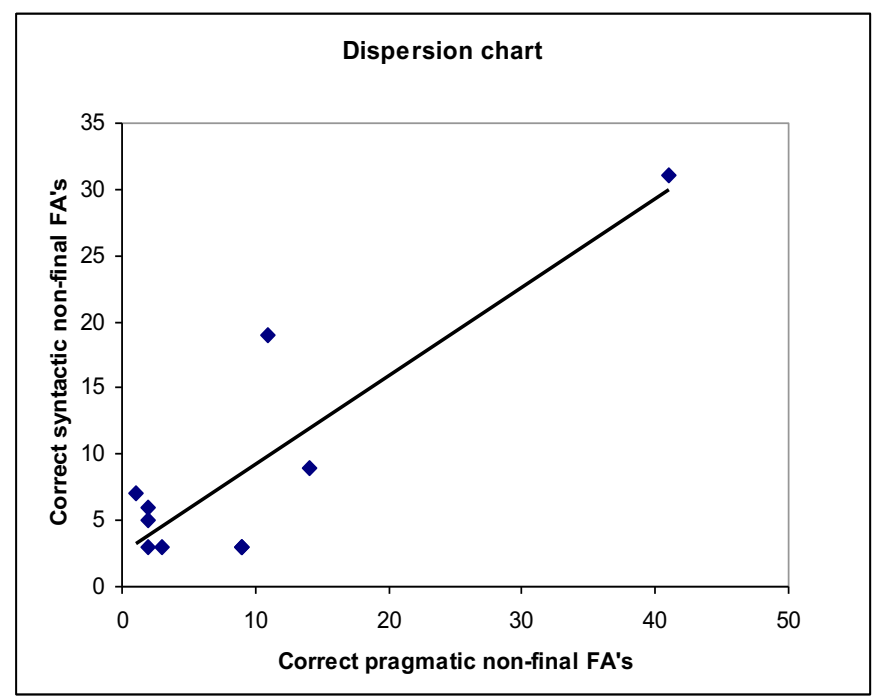

Figure 3: Dispersion chart of correct non-final focus accents (syntactic vs. pragmatic)

We then compared our previous study with the current one in order to check whether the performances of the single subjects were similar in elicited (read) and semi-spontaneous speech. More specifically, we placed the number of correct non-final focus accents of each test person

\footnotetext{
${ }^{17}$ Only 9 dots are visible in the chart because TS06 and TS07 coincide: both have 9 correct pragmatic and 3 correct syntactic non-final focus accents.
} 
in the two different settings side by side, as can be seen in fig. 4, where subjects are ranked leftto-right according to their total number of correct non-final focus accents.

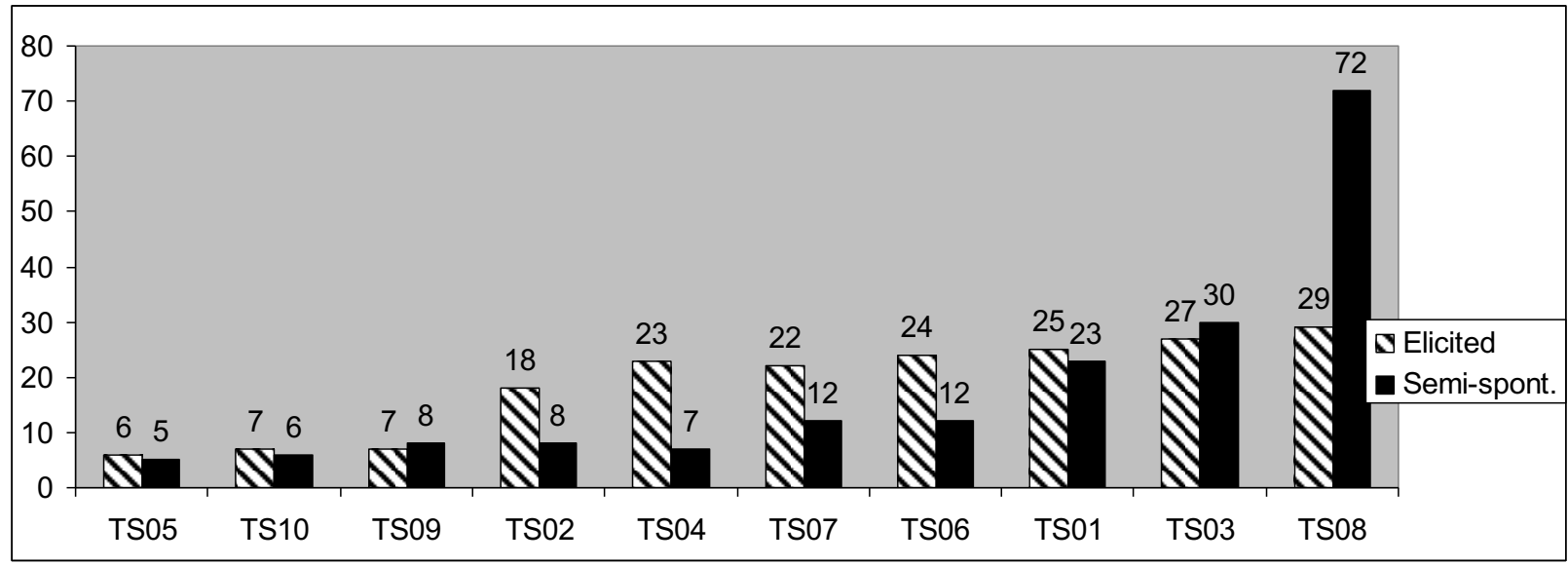

Figure 4: Comparison of correct non-final focus accents in elicited vs. semi-spontaneous speech within the same test subjects (TS)

In this case, Spearman's rank correlation coefficient was extremely high (rho $=0.90, \mathrm{p}<.001$ ), indicating that the use of non-final focus accents in elicited speech is closely correlated with that same use in semi-spontaneous speech. This means that we can confirm hypothesis $\mathrm{C}$ according to which the ability to realize non-final accents is independent of the experimental setting and the speech style. Quite surprising is the high number of correct non-final focus accents of test subject TS08, especially in semi-spontaneous speech. No other subject has more than twice as many correct accents in semi-spontaneous speech than in elicited (read) speech. This result can be explained by two reasons. First of all, TS08 is the only learner who spent 6 months in a German speaking country (cf. section 4.2) and probably has well acquired the non-final focus accent of the target language. Secondly, this subject has got a comparatively very high speech rate. While in the elicited speech experiment the maximum number of non-final focus accents was 35, in the semi-spontaneous speech study the number of non-final focus accents depends on speech rate as well as on prosodic acquisition.

\section{$5 \quad$ Discussion and summary}

Over the last years, growing cross-linguistic evidence suggests that learners of a foreign language start with a phrase-final focus accent and highlight the last content word in a phrase. The fact that end stress is observed in early learner varieties, irrespective of the relevant L1, points to focus accent placement at the edge of a prosodic phrase as unmarked prosodic universal (Zerbian 2015, cf. Paschke/Vogt 2015, Gut 2009, Rasier/Hiligsmann 2007, Grosser 1997).

According to Eckman's Markedness Differential Hypothesis regarding the acquisition of a L2, "those areas of the target language that differ from the native language and are more marked than the native language will be difficult" (Eckman 2004: 530). In the case at hand - German L2 as target language - marked (i. e. non-final) focus accents are very frequent and are likely to cause problems for Italian speakers given that in their L1 the unmarked phrase final focus accent is largely prevailing. 
In this contribution we investigated how Italian L1 speakers master the placement of non-final focus accents in German.

We compared two different contexts in which in German, but not in Italian, non-final focus accents on sentence level arise: a) absence of prominence on post-focal given information (pragmatically determined de-accentuation); b) lack of prominence on (parts of) the predicate in OV structures with focus accent on the argument (syntactically determined de-accentuation). The aim of the study was to test if one of the two contexts is mastered better by the learners at a specific stage of acquisition (B2 as target level).

The dataset as a whole reveals that the learners of German L2 do not use non-final focus accents at random: most of the non-final focus accents are used correctly which confirms our hypothesis A (cf. section 4.1.). Moreover, this large number of correct non-final focus accents was very evenly distributed between syntactically and pragmatically determined focus accents (hypothesis B1).

According to the idea that pragmatic de-accentuation is not easier to acquire than the syntactic one we also expected a significant correlation between the two types of de-accentuation for the single test subjects (hypothesis B2). The fact that learners of different levels of (prosodic) acquisition display different numbers of non-final focus accents, but with a substantial balance between the two types of de-accentuation, supports the idea that both types of de-accentuation show up and are acquired simultaneously. However, the second part of hypothesis B which predicts a significant correlation between the two types of correct de-accentuation within the single test subjects, has to be rejected because, although there is a correlation, it is not statistically significant. Moreover, generalizations about individual acquisition processes should be backed up by longitudinal data.

Further studies might produce stronger evidence by analysing longer stretches of semi-spontaneous speech (achieving higher numbers of realizations which statistically tend to be more balanced) and/or by calculating the percentages of correct realizations in relation to the whole set of utterances in which a certain type of de-accentuation is required, including those with incorrect phrase-final pitch-accents. An analysis which takes into consideration all the utterances with (supposed) non-final focus exponents might reveal that the percentage of correct non-final focus accents is approximately the same even if the absolute numbers are quite different in broad and narrow focus contexts.

Finally, we compared the scores of each L2-speaker with the results of our previous experimental study (Paschke/Vogt 2015). In this regard, we observed a very high intra-speaker correlation between read speech and semi-spontaneous speech (hypothesis $\mathrm{C}$ ). In other words, the controlled experimental setting with read speech is likely to produce results that are similar to a more realistic setting of language use. Both settings seem to produce very similar rankings with respect to the subjects' ability to use correct non-final focus accents (whether syntactically or pragmatically determined).

To sum up, our examination of the semi-spontaneous speech produced by Italian intermediate learners of German L2 provides evidence for the claim that (potentially universal) pragmatic 
cues do not constitute an advantage compared to (target language) syntactic rules in the acquisition of non-final focus accents: pragmatics does not "beat" syntax. In our view, this result is consistent with Eckman's Markedness Differential Hypothesis in the sense that non-final focus accents are marked, irrespective of their nature, and therefore difficult to acquire in the target language. On the other hand, once and to the extent that learners overcome the negative transfer of the unmarked rightmost focus accent, pragmatic as well as syntactic de-accentuation can occur in the learner variety. This might be explained by a learner grammar in which the nuclear accent is no longer aligned to a fixed position in the intonational phrase, but to the same word that would be accented in L1: the word in narrow focus in the case of pragmatic de-accentuation, the nominal head of an argument in the case of syntactic de-accentuation.

\section{References}

Avesani Cincia/Vayra, Mario (2005): "Accenting, deaccenting and information structure in Italian dialogues”. In: Dybkjaer, Laila/Minker, Wolfgang (eds.): Proceedings of the 6th SIGdial Workshop on Discourse and Dialogue. Dodrecht, Springer: 19-24.

Avesani, Cinzia et al. (2015): "Prosody and Information Status in Italian and German L2 Intonation". In: Chini, Marina (ed.): Il parlato in [italiano] L2: aspetti pragmatici e prosodici /[Italian] L2 spoken discourse: pragmatic and prosodic aspects. Milano, Angeli: 93-116.

Baumann, Stefan/Kügler, Frank (2015): "Prosody and information status in typological perspective - Introduction to the Special Issue”. Lingua 165, B: 179-182. doi: 10.1016/j.lingua.2015.08.001

Baumann, Stefan/Riester, Arndt (2013): “Coreference, Lexical givenness and prosody in German". Lingua 136: 16-37.

Bocci, Giuliano (2008): "On the Syntax-Prosody Interface: an analysis of the prosodic properties of postfocal material in Italian and its implications". Nanzan Linguistics: Special Issue 5: $13-42$.

Bocci Giuliano/Avesani, Cinzia (2015): "Can the metrical structure of Italian motivate focus fronting?" In: Ur Shlonsky (ed.): Beyond Functional Sequence. The cartography of syntactic structures. Oxford: Oxford University Press: 23-41. (= Oxford Studies in Comparative Syn$\operatorname{tax} 10)$.

Chafe, Wallace (1976): “Givenness, Contrastiveness, Definiteness, Subjects, Topics and Point of View". In: Charles Li (ed.): Subject and Topic. New York, Academic Press: 25-56.

Chafe, Wallace (1994): Discourse, Consciousness, and Time. Chicago/London: University of Chicago Press.

Chen, Aoju (2005): Universal and language-specific perception of paralinguistic intonational meaning. Utrecht: LOT.

Cruttenden Alan (2006): “The de-accenting of given information: a cognitive universal?" In: Bernini, Giuliano/Schwartz, Marcia L. (eds.): Pragmatic Organization of Discourse in the Languages of Europe. Berlin/New York, de Gruyter: 311-355.

Eckman, Fred R. (1987): "Markedness and the contrastive analysis hypothesis". In: Ioup, Georgette/Weinberger, Steven H. (eds.): Interlanguage Phonology. The Acquisition of a Second Language Sound System. Cambridge: Newbury House Publishers: 55-69 (= reprint of Language learning 27 (1977: 315-330). 
Eckman, Fred R. (2004): "From phonemic differences to constraint rankings". Studies in Second Language Acquisition 26: 513-549.

Face, Timothy L./D'Imperio, Mariapaola (2005): "Reconsidering a Focal Typology: Evidence from Spanish and Italian”. Italian Journal of Linguistics 17: 271-289.

Fery, Caroline (2011): "German sentence accents and embedded prosodic phrases". Lingua 121: 1906-1922.

Féry, Caroline (2013): "Focus as prosodic alignment". Natural Language/Linguistic Theory 31/3: 683-734.

Grice, Martine/D'Imperio, Mariapaola/Savino, Michelina/Avesani, Cinzia (2005): "Strategies for Intonation Labelling across Varieties of Italian”. In: Sun-Ah Jun (ed.): Prosodic Typology: an Approach through Tone and Break Indices. Oxford, Oxford University Press: 362389.

Grice, Martine/Baumann, Stefan (2007): "An introduction to intonation - functions and models”. In: Trouvain, Jürgen/Gut, Ulrike (eds.): Non-native prosody: phonetic description and teaching practice. Berlin/New York: Mouton de Gruyter: 25-52.

Grosser, Wolfgang (1997): "On the acquisition of tonal and accentual features of English by Austrian learners". In: James, Allan R./Leather, Jonathan (eds.): Second language speech: Structure and process. Berlin, Mouton de Gruyter: 211-228.

Gussenhoven, Carlos (1992): "Sentence accents and argument structure”. In: Roca, Iggy M. (ed.): Linguistic Models: Thematic Structure: Its Role in Grammar. Berlin/New York: Mouton de Gruyter: 79-106.

Gussenhoven, Carlos (2004): The Phonology of tone and intonation. Cambridge: Cambridge University Press.

Gut, Ulrike (2009): Non-native speech: A corpus-based analysis of phonological and phonetic properties of L2 English and German. Frankfurt/M. etc.: Lang.

Gut, Ulrike/Pillai, Stefanie (2014): "Prosodic marking of information structure by Malaysian speakers of English". Studies in Second Language Acquisition 36: 283-302.

Hartmann, Jutta M./Susanne Winkler (2013): "Investigating the role of information structure triggers". Lingua 136: 1-15.

Krifka, Manfred (2008): "Basic notions of information structure". Acta Linguistica Hungarica 55: 243-276.

Kügler, Frank/Féry, Caroline (2016): "Post-focal downstep in German". Language and Speech 16/2, DOI:10.1177/0023830916647204

Ladd, D. Robert (1980): The Structure of Intonational Meaning: Evidence from English. Bloomington: Indiana University Press.

Ladd, D. Robert (1996): Intonational phonology. Cambridge: Cambridge University Press.

Lombardi Vallauri, Edoardo (2010): “Focalizzazioni”. In: Simone, Raffaele (ed.): Enciclopedia dell'Italiano. Roma, Istituto della enciclopedia italiana: 469-477.

Maastricht, Lieke van/Krahmer, Emiel/Swerts, Marc (2016): "Prominence Patterns in a Second Language: Intonational Transfer From Dutch to Spanish and Vice Versa". Language learning 1/66: 124-158.

Nübling, Damaris et al. (2006): Historische Sprachwissenschaft des Deutschen. Eine Einführung in die Prinzipien des Sprachwandels. Tübingen: Narr. 
O'Brien, Mary/Gut, Ulrike (2011): "Phonological and phonetic realisation of different types of focus in L2 speech“. In: Wrembel, Magdalena/Kul, Małgorzata/Dziubalska-Kołaczyk, Katarzyna (eds.): Achievements and Perspectives in SLA of Speech: New Sounds 2010, vol. I. Frankfurt/M. etc., Lang: 331-336.

Paschke, Peter/Vogt, Barbara (2015): "Non-final focus accents in the speech of advanced Italian learners of German”. Linguistik online 72: 8-110. http://dx.doi.org/10.13092/lo.72.1974.

Poletto, Cecilia/Giuliano Bocci (2016): "Syntactic and Prosodic Effects of Information Structure in Romance". In: Féry, Caroline/Ishihara, Shinichiro (eds.): The Oxford Handbook of Information Structure. Oxford: Oxford University Press: 641-662.

Ramirez Verdugo, Dolores (2002): "Non-native interlanguage intonation systems: a study based on a computerized corpus of Spanish learners of English". ICAME Journal 26: 115132.

Rasier, Laurent/Hiligsmann, Philippe (2007): "Prosodic transfer from L1 to L2. Theoretical and methodological issues". Nouveaux cahiers de linguistique française 28: 41-66.

Rasier, Laurent/Hiligsmann, Philippe (2009): "Exploring the L1-L2 Relationship in the L2 Acquisition of Prosody" (unpublished conference). Oxford. www .education.ox.ac.uk//wp-content/uploads/2010/08/RasierHiligsmann.doc [04.11.2016].

Samek-Lodovici, Vieri (2010): "Final and non-final focus in Italian DPs". Lingua 120: 802818.

Selkirk, Elisabeth O. (1995): “Sentence prosody: Intonation, stress and phrasing”. In: Goldsmith, John A. (ed.): Handbook of phonological theory. Cambridge/Massachusetts, Blackwell: 550-569.

Selkirk, Elisabeth O. (2011): “The Syntax-Phonology Interface”. In: Goldsmith, John A./Yu, Alan C.L./Riggle, Jason (eds.): The handbook of phonological theory. Chichester, WileyBlackwell: 435-484.

Selting, Margret/Auer, Peter et al. (2009): „Gesprächsanalytisches Transkriptionssystem 2 (GAT 2)“. Gesprächsforschung 10: 353-402. www.gespraechsforschung-ozs.de/heft2009/ px-gat2.pdf [4.11.2016].

Swerts, Marc/Krahmer, Emiel/Avesani, Cinzia (2002): "Prosodic marking of information status in Dutch and Italian: A comparative analysis". Journal of Phonetics 30: 629-654.

Truckenbrodt, Hubert (2006): "Phrasal stress". In: Brown, Keith (ed.): The Encyclopedia of Languages and Linguistics, $2^{\text {nd }}$ edition. Vol. 9. Oxford, Elsevier: 572-579.

Uhmann, Susanne (1991): Fokusphonologie: eine Analyse deutscher Intonationskonturen in Rahmen der nicht-linearen Phonologie. Tübingen: Niemeyer.

Vallduví, Enric (1991): "The role of plasticity in the association of focus and prominence". Eastern States Conference in Linguistics 7: 295-306.

Zerbian, Sabine (2015): "Markedness Considerations in L2 Prosodic Focus and Givenness marking”. In: Delais-Roussarie, Elisabeth/Avanzi, Mathieu/Herment, Sophie (eds.): Prosody and Language in Contact. L2 Acquisition, Attrition and Languages in Multilingual Situations. Berlin/Heidelberg, Springer: 7-27.

Zubizarreta, Maria Luisa (2016): "Nuclear Stress and Information Structure”. In: Féry, Caroline/Ishihara, Shinichiro (eds.): The Oxford Handbook of Information Structure. Oxford, Oxford University Press: 165-76. 